\title{
Chronic Development of Ischaemic Mitral Regurgitation during Post-Infarction Remodelling
}

\author{
Uwe Nixdorffa $^{\mathrm{a}}$ Lutz Klinghammer $^{\mathrm{a}}$ Gertrud Wüstefeld ${ }^{\mathrm{b}}$ \\ Susanne Mohr-Kahaly ${ }^{b}$ Ralph Stephan von Bardeleben ${ }^{b}$ \\ Second Medical Clinics, ${ }^{a}$ Friedrich Alexander University, Erlangen-Nuremberg, and \\ bJohannes Gutenberg University, Mainz, Germany
}

\section{Key Words}

Left-ventricular remodelling $\cdot$ Mitral regurgitation •

Myocardial infarction $\cdot$ Prognosis

\begin{abstract}
Background/Aims: Mitral regurgitation (MR) following myocardial infarction (MI) may be a (sub)acute complication which independently predicts reduced survival. We sought to evaluate the chronic development of MR as potential consequence of left-ventricular (LV) remodelling, the latter being a long-term process. Methods and Results: Retrospectively, 103 post-MI patients were included according to a standardised Doppler echocardiogram $<3$ months following $\mathrm{MI}(20 \pm 25$ days post-MI) and a follow-up examination $>6$ months after the first examination $(5.1 \pm 3.1$ years postMI). Patients were clinically followed up for $7.6 \pm 2.7$ years. Group I patients were defined as those showing new development or deterioration in one of three grades of MR, and group II those without this criterion (MR grade acute 0.17 vs. $0.27, p=0.7$, and chronic 1.53 vs. $0.19, p<0.0001$ ). Patient characteristics were similar in respect of age, gender, size and location of infarction. However, group I patients had coronary artery disease with more vessels involved. With regard to echocardiographic parameters of significantly enlarged LV chamber size in group I vs. group II, the significant decrease in LV performance was more pronounced and occurred concomitant with a higher degree of symptomatic congestive heart failure and greater need for heart failure medications in group I. Mortality in group I patients was 39
\end{abstract}

versus $9 \%$ in group II patients $(p=0.0002)$, approximating an odds ratio of 6.4697 (95\% confidence interval: 2.21118.931). Conclusion: First of all, this retrospective study indicates that MR may be detected in patients after MI during a long-term follow-up most probably due to geometric distortions of LV remodelling resulting in a significantly higher mortality. Since this process is known to become irreversible at a certain point, serial echocardiography may help to detect MR in post-MI patients and thus pave the way for appropriate treatment.

Copyright $\odot 2007$ S. Karger AG, Basel

\section{Introduction}

Despite advances in the treatment of acute myocardialinfarction (MI), secondary mitral regurgitation (MR) persists as a possible acute complication [1-7]. Studies have demonstrated different aspects of its pathophysiology such as regional wall motion abnormalities inducing ventricular and papillary muscle dysfunction [6], (partial) rupture of papillary muscles [6, 7], restricted leaflet closure as well as leaflet tethering [8] and dilatation of the mitral annulus parallel to left-ventricular (LV) dilatation [4]. Furthermore, the independent prognostic impact of these events has been sufficiently confirmed [2-5]. However, the consequences of a more chronic development of clinically significant MR are still rather unknown, although, principally, LV remodelling may result in insufficient mitral valve coaptation.

\section{KARGER}

Fax +4161306 1234 E-Mail karger@karger.ch www.karger.com

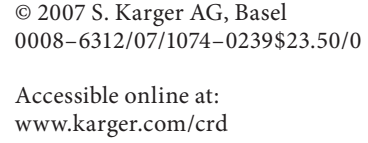

Assist. Prof. Uwe Nixdorff, MD, FESC

Turmhügelweg 22

DE-91058 Erlangen (Germany)

Tel. +49 9131615 240, Fax +499131616070

E-Mail uwe.nixdorff@t-online.de 
Our aim was to evaluate the chronic development or deterioration in MR in post-MI patients by serial clinical and Doppler echocardiographic follow-up. The study design was retrospective, and recruitment resulted from a typical MI population of the University Clinic of Mainz, Germany. In a further MI population treated at the same time and location, development of MR was ruled out. Long-term clinical, echocardiographic, and prognostic parameters were compared between both groups to clarify the relative significance and prognosis of chronic MR in post-MI LV remodelling.

\section{Patients and Methods}

\section{Patients}

The study included clinical data of 400 consecutive patients with an acute MI, defined as an increase in cardiac enzyme levels (creatine kinase, CK, $>2 \times$ the upper limit of normal), presence of ST-segment elevation in the initial ECG and subsequent development of new $Q$ waves as well as acute symptoms of ischaemic chest pain. The patients had been admitted to hospital between October 13, 1983, and January 30, 1995, and treated acutely and chronically at the investigating clinic, including at least one quantitative transthoracic Doppler echocardiogram.

Patients were retrospectively screened for the following inclusion criteria: (1) Standardised quantitative transthoracic Doppler echocardiography was within the time window between acute MI and 3 months post-MI ( $20 \pm 25$ days post-MI); (2) The time frame between this first and a second, standardised echocardiography during follow-up had to be at least 6 months $(5.1 \pm 3.1$ years postMI). Besides the clinical follow-up by the treating practitioners, patients were routinely advised to present for re-examination at the university outpatient clinics for research purposes (independent of this retrospective study).

Intrinsic alterations in the mitral valve (such as rheumatic or inflammatory disease) had to be excluded by echocardiography as well as (sub)acute severe MR, a typical complication of MI (e.g. papillary muscle rupture) and coinciding valvular disease (e.g. aortic stenosis $\geq$ grade I and aortic regurgitation $>$ grade I) or congenital heart disease. Patients with preceding MI prior to the index MI or cardiac surgery were excluded. Further exclusion criteria were bundle branch block, atrial fibrillation or flutter. None of the patients obtained resynchronization therapy.

In the consecutive series of the $400 \mathrm{MI}$ patients, 103 patients met the eligibility criteria. The main restriction of this study was the lack of chronic follow-up and the time schedule of echocardiographic examinations. Two thirds of the patients were acutely admitted to the emergency department, and one third was referred from secondary and tertiary hospitals mainly for the purpose of invasive assessment.

Patients were classified into two groups according to the following MR criteria:

Group I consisted of patients in whom MR had newly developed between both echocardiographic examinations or if MR had deteriorated by at least one grade of four (none, mild, moderate and severe). Group II patients neither had MR nor changes in their MR grade during the echocardiographic follow-up, or even demonstrated an improvement in MR.

The investigation conforms to the principles outlined in the Declaration of Helsinki.

\section{Echocardiography}

Echocardiography was performed with the different sector scanners GE Vingmed CFM800, Toshiba SSH 160A as well as Aloka SSZ 203 with transducers providing scanning frequencies of 2.5 and $3.5 \mathrm{MHz}$. Recordings and measurements adhered strictly to German guidelines [9], which are still compulsory in a current version [10], as well as the guidelines of the American Society of Echocardiography [11]. Gain settings and grey scale were optimised in every single patient avoiding 'blooming' on the one hand and 'dropouts' on the other. Bedside measurements were immediately visualised from digitised images and cine loops stored by the investigating echo machine which provided built-in quantitative programs. Normal values were established in the echocardiographic laboratory of the investigating university hospital.

Echocardiographic assessment included M-mode scanning, in which the following parameters were measured in the parasternal long axis view: (1) LV end-diastolic diameter index (LVDDI, in $\mathrm{cm} / \mathrm{m}^{2}$; normal value: $2.0-3.2 \mathrm{~cm} / \mathrm{m}^{2}$ ); (2) LV end-systolic diameter index (LVDSI; in $\mathrm{cm} / \mathrm{m}^{2}$ ); (3) LV fractional shortening (LVFS, in \%, derived from: LVFS = (LVDDI - LVDSI $) /$ LVDDI $\times$ 100; normal value: 25-35\%); (4) end-diastolic interventricular septum (IVSd, in $\mathrm{cm}$ ) and inferior myocardial wall thickness (IWd, in $\mathrm{cm}$ ), measured at end-diastole (normal values: IVS as well as IW $=0.5-1.3 \mathrm{~cm}$ ); (5) LV muscle mass (LVmass, in $\mathrm{g} / \mathrm{cm}^{2}$ ) derived from: $\mathrm{LVmass}=1.5\left[(\mathrm{LVDD}+\mathrm{IW}+\mathrm{IVS})^{3}-\mathrm{LVDD}^{3}\right.$; normal value: $\leq 132 \mathrm{~g} / \mathrm{m}^{2}$ ]; (6) left-atrial diameter (LAD) at end-systole (in cm; normal value: $2.5-4.5 \mathrm{~cm}$ ); (7) right-ventricular enddiastolic diameter index (RVDDI; in $\mathrm{cm} / \mathrm{m}^{2}$; normal value $=0.5-$ $1.7 \mathrm{~cm} / \mathrm{m}^{2}$ ), and (8) right pulmonary artery diameter index (RPAI; in $\mathrm{cm} / \mathrm{m}^{2}$; normal value $<1.1 \mathrm{~cm} / \mathrm{m}^{2}$ ).

In two-dimensional echocardiography, the following measurements were taken in apical scanning projections (2- and 4-chamber view): (1) end-diastolic volume index (EDVI, in $\mathrm{ml} / \mathrm{m}^{2}$; normal value $=43-83 \mathrm{ml} / \mathrm{m}^{2}$ ); volume algorithm was the disc summation method also known as modified Simpson's rule, which is least dependent on geometric distortions [11]; (2) end-systolic volume index (ESVI, in $\mathrm{ml} / \mathrm{m}^{2}$; normal value $\left.=21-33 \mathrm{ml} / \mathrm{m}^{2}\right)$, and (3) ejection fraction $(\mathrm{EF}$, in $\%$, normal value $=48-71 \%)$ calculated according to the formula: EF = EDVI - ESVI/EDVI $\times 100$.

All patients demonstrated regional wall motion abnormalities indicating transmural MI; however, in this study, the extent of MI was not documented quantitatively.

Colour Doppler echocardiography indicated the presence/absence and semi-quantitative degree of MR. Grade 0 was defined as no $\mathrm{MR}$, grade I as traces of MR, grade II as a regurgitation jet not reaching the atrial ceiling (moderate MR) and grade III as a regurgitation jet not only reaching the atrial ceiling but almost filling the whole atrial cavity, and, often, regurgitation into the pulmonary veins was observed (severe MR). The Doppler spectrum was adjusted according to the Nyquist limit just avoiding aliasing.

\section{Coronary Angiography}

Coronary angiography was performed in an averaged time window of 6 days after MI. The degree of coronary stenosis was judged by experienced cardiologists. The criterion for significant 
Table 1. Patient characteristics and MI history

\begin{tabular}{lccc}
\hline Characteristics & $\begin{array}{c}\text { Group I } \\
(\mathrm{n}=36)\end{array}$ & $\begin{array}{l}\text { Group II } \\
(\mathrm{n}=67)\end{array}$ & $\begin{array}{c}\mathrm{p} \\
\text { value }\end{array}$ \\
\hline Age, years & $65.7 \pm 10.7$ & $62.7 \pm 9.6$ & 0.2 \\
Gender, male & $29(80 \%)$ & $58(87 \%)$ & 0.6 \\
Arterial hypertension & $20(55 \%)$ & $38(56 \%)$ & 0.8 \\
Acute MR & 0.17 & 0.27 & 0.7 \\
Chronic MR, 4 years & 1.53 & 0.19 & $<0.0001$ \\
Location of infarction & & & 0.8 \\
$\quad$ AMI & $17(47 \%)$ & $34(51 \%)$ & \\
$\quad 19 I$ & $5(14 \%)$ & $33(49 \%)$ & 0.5 \\
Reinfarction & $906.4 \pm 665.5$ & $857.6 \pm 681.9$ & 0.7 \\
Size of infarction: CK, IU/1 & & & 0.01 \\
Coronary anatomy & $22(61 \%)$ & $51(76 \%)$ & \\
Acute catheterisation performed & $0(0 \%)$ & $2(4 \%)$ & \\
$\quad$ Any relevant CAD & $7(32 \%)$ & $26(51 \%)$ & \\
$\quad$ 1-vessel-disease & $5(23 \%)$ & $14(27 \%)$ & 0.7 \\
$\quad$ 2-vessel-disease & $10(45 \%)$ & $9(18 \%)$ & 0.3 \\
$\quad$ 3-vessel-disease & $14(39 \%)$ & $23(34 \%)$ & \\
Thrombolysis & $5(23 \%)$ & $20(39 \%)$ & \\
PCI & & & \\
\hline
\end{tabular}

The numbers of the patients (\%) are shown, except for age and size of the infarction (means $\pm \mathrm{SD}) . \mathrm{AMI} / \mathrm{IMI}=$ Anterior/inferior $\mathrm{MI} ; \mathrm{CAD}=$ coronary artery disease. stenosis was a luminal narrowing of $\geq 50 \%$ in at least one projection. Percutaneous coronary intervention (PCI) procedures were documented.

\section{Clinical Data and Follow-Up}

Characteristics of the patients retrieved from the medical records were personal data, medical history and clinical parameters.Personal data included age (years) and sex (male/female). Medical history comprised date of MI, location of infarction [anterior/inferior MI), maximal concentration of CK, acute MI treatment (thrombolysis and/or PCI), and, for deceased patients, cause of death (reinfarction, cardiogenic shock, or arrhythmogenic, or non-cardiologic disease), and time interval between MI and death. Clinical parameters were the absence/presence of angina pectoris according to the Canadian Cardiovascular Society (grade I-IV) and congestive heart failure symptoms according to the New York Heart Association (grade I-IV). These classifications were documented in the subacute state (at the time of the first echocardiogram $<3$ months post-MI, $20 \pm 25$ days post-MI) and in the chronic state, i.e. at the time of the follow-up echocardiogram ( $>6$ months after the initial echocardiogram, $5.1 \pm 3.14$ years post-MI) and later by phone call (7.6 \pm 2.7 years post-MI). Cardiovascular medications were also assessed at these three time points ( $\beta$-blockers, nitrates, glycosides, ACE inhibitors and diuretics). In case of deaths, date and cause of death were also assessed.

Statistical Analysis

For statistical analyses, SPSS 12.01 and PRISM 4.02 (SPSS $^{\odot}$ and GraphPad Software ${ }^{\odot}$ ) were used. Quantitative measurements are expressed as means and standard deviations for patients of groups I and II, respectively. Nominal parameters (sex, location of infarction, reinfarctions, thrombolysis, medication, coronary anatomy, PCI and cause of death) are given as numbers and frequencies in percent. Comparisons of quantitative and ordinal measures of the two independent populations were assessed by Student's t test and Mann-Whitney U test for independent values. A p value $<0.05$ was defined as significant. For qualitative parameters, two-sided $\mathrm{p}$ values were calculated from tables with two rows and two columns using Fisher's exact test. For other contingency tables, the $\chi^{2}$ test was used. A special $\chi^{2}$ test for trend was applied to analyse 0 -/3-vessel disease.

Survival rates were expressed in per cent for the different groups according to the Kaplan-Meier-curves (time span 60 months). A log-rang test compared the survival curves of groups; a $p$ value $<0.05$ was again considered to be significant.

\section{Results}

\section{Study Population}

According to group definitions, MR severities differed. MR grade did not significantly differ in the acute stage ( $<3$ months; $20 \pm 25$ days post-MI; 0.17 vs. 0.27 ; $\mathrm{p}=0.7$ ), only at the follow-up (at least 6 months after the initial echocardiogram; $5.1 \pm 3.1$ years post-MI; 1.53 vs. $0.19 ; \mathrm{p}<0.0001 ;$ table 1$)$. The patient characteristics of 
Table 2. Symptoms/clinical status and medication during the follow-up

\begin{tabular}{|c|c|c|c|}
\hline Status and medication & $\begin{array}{l}\text { Group I } \\
(n=67)\end{array}$ & $\begin{array}{l}\text { Group II } \\
(\mathrm{n}=36)\end{array}$ & $\mathrm{p}$ \\
\hline \multicolumn{4}{|l|}{ AP CCS I-IV } \\
\hline Acute stage & $2.3 \pm 0.8$ & $2.0 \pm 0.8$ & 0.1 \\
\hline After 5.1 years & $2.1 \pm 0.8$ & $1.7 \pm 0.9$ & 0.027 \\
\hline After 7.6 years & $1.6 \pm 0.7$ & $1.4 \pm 0.6$ & 0.3 \\
\hline \multicolumn{4}{|c|}{ Heart failure: NYHA I-IV } \\
\hline Acute stage & $2.0 \pm 0.8$ & $2.0 \pm 0.8$ & 0.9 \\
\hline After 5.1 years & $2.5 \pm 1.0$ & $1.7 \pm 0.8$ & 0.001 \\
\hline After 7.6 years & $1.7 \pm 0.7$ & $1.6 \pm 0.7$ & 0.5 \\
\hline \multicolumn{4}{|l|}{ Medication } \\
\hline \multicolumn{4}{|l|}{ Acute stage } \\
\hline$\beta$-Blocker & $8(22 \%)$ & $21(31 \%)$ & 0.3 \\
\hline Nitrates & $25(69 \%)$ & $35(53 \%)$ & 0.2 \\
\hline Glycosides & $13(36 \%)$ & $14(21 \%)$ & 0.2 \\
\hline ACE inhibitors & $10(28 \%)$ & $14(21 \%)$ & 0.5 \\
\hline Diuretics & $13(36 \%)$ & $14(21 \%)$ & 0.2 \\
\hline \multicolumn{4}{|l|}{ After 5.1 years } \\
\hline$\beta$-Blocker & $9(26 \%)$ & $17(27 \%)$ & 0.7 \\
\hline Nitrates & $18(53 \%)$ & $27(44 \%)$ & 0.4 \\
\hline Glycosides & $15(44 \%)$ & $6(10 \%)$ & $<0.001$ \\
\hline ACE inhibitors & $22(65 \%)$ & $17(27 \%)$ & 0.001 \\
\hline Diuretics & $18(53 \%)$ & $11(17 \%)$ & $<0.001$ \\
\hline \multicolumn{4}{|l|}{ After 7.6 years } \\
\hline$\beta$-Blocker & $6(35 \%)$ & $14(29 \%)$ & 0.5 \\
\hline Nitrates & $12(71 \%)$ & $28(57 \%)$ & 0.4 \\
\hline Glycosides & $6(35 \%)$ & $7(14 \%)$ & 0.1 \\
\hline ACE inhibitors & $11(65 \%)$ & $15(31 \%)$ & 0.021 \\
\hline Diuretics & $7(41 \%)$ & $13(27 \%)$ & 0.1 \\
\hline
\end{tabular}

Numbers of patients (\%) are shown. Total number of patients (group I/II) at the acute stage (20 days after MI) n = 36/67; after 5.1 years $n=34 / 62$, and after 7.6 years $n=17 / 49$. AP $=$ Angina pectoris; CCS = Canadian Cardiovascular Society (class I-IV); NYHA = New York Heart Association (class I-IV).

Table 3. Mortality data and causes of death during the follow-up

\begin{tabular}{lcll}
\hline Mortality and causes & $\begin{array}{c}\text { Group I } \\
(\mathrm{n}=36)\end{array}$ & $\begin{array}{l}\text { Group II } \\
(\mathrm{n}=67)\end{array}$ & $\begin{array}{l}\mathrm{p} \\
\text { value }\end{array}$ \\
\hline Deaths, $\mathrm{n}$ & $14(39 \%)$ & $6(9 \%)$ & 0.0002 \\
$\quad$ Cardiogenic shock & $10(71 \%)$ & $2(33 \%)$ & 0.2 \\
Ventricular fibrillation & $2(14 \%)$ & $0(0 \%)$ & 0.9 \\
Reinfarction & $0(0 \%)$ & $0(0 \%)$ & - \\
Non-cardiological & $1(7 \%)$ & $3(50 \%)$ & 0.06 \\
Unknown & $1(7 \%)$ & $1(17 \%)$ & 0.5 \\
\hline
\end{tabular}

Numbers of patients (\%) are shown. both groups did not differ at baseline (table 1). The majority of the patients did not develop MR during followup. It is also pointed out that the sites of infarction are equally distributed in both groups, i.e. one half of the patients suffered from anterior and the other half from inferior MI, which holds true for both groups (nonsignificant). Furthermore, infarction extents defined by maximal CK concentrations were comparable in both groups (nonsignificant). However, with respect to invasive data (coronary anatomy), it became evident that patients in group II demonstrated less severe coronary artery disease $(\mathrm{p}=0.0138)$; however, acute MI treatments (thrombolysis and PCI) did not differ (table 1).

\section{Clinical Follow-Up}

The incidence of symptomatic coronary artery disease (angina pectoris) significantly increased in patients in group I during follow-up $(5.1 \pm 3.1$ years post-MI; $\mathrm{p}=$ 0.027 ), which was even more pronounced in the presence of symptoms of congestive heart failure $(p=0.001)$. However, the phone calls $(7.6 \pm 2.7$ years post-MI) revealed that these differences no longer existed, most likely due to the exclusion of severely ill and even deceased patients during the follow-up (tables 2, 3). Differences in symptomatic features were in parallel with cardiovascular medications indicated for congestive heart failure (table 2). The phone calls succeeded in gaining information from only $72 / 103$ patients because 20 patients had died and 11 could not be contacted, including 2 who refused to give any information.

\section{Echocardiographic Follow-Up}

Echocardiographic data obtained in the serial followup are presented in table 4 . No differences in any echocardiographic parameter could be found in the acute stage. Changes were observed only in long-term followup data. The LV cavity size increased only in group I patients (LVDDI and LVDSI increased, EDVI and ESVI increased) concomitant with an increase in LVmass in group I and a decrease in group II patients. LV performance deteriorated in group I (LVFS decreased and EF decreased), whereas LV function was almost unchanged in group II. LA size increased more in group I than in group II. Surrogate parameters for pulmonary hypertension increased in group I patients but decreased in group II patients (RVDDI and RPAI decreased).

Survival

Survival curves are shown in figure 1. Interestingly, survival did not differ within the first 27 months. Espe- 
Table 4. Echocardiographic data (means \pm SD) 20 days (acute) and 5.1 years after $\mathrm{MI}(\mathrm{FU})$

\begin{tabular}{|c|c|c|c|}
\hline & $\begin{array}{l}\text { Group I } \\
(\mathrm{n}=36)\end{array}$ & $\begin{array}{l}\text { Group II } \\
(\mathrm{n}=67)\end{array}$ & $\begin{array}{l}\mathrm{p} \\
\text { value }\end{array}$ \\
\hline \multicolumn{4}{|c|}{ LVDDI, $\mathrm{cm} / \mathrm{m}^{2}$} \\
\hline Acute & $3.0 \pm 0.7$ & $2.8 \pm 0.5$ & 0.6 \\
\hline FU & $3.2 \pm 0.7$ & $2.9 \pm 0.5$ & $<0.01$ \\
\hline \multicolumn{4}{|c|}{ LVDSI, $\mathrm{cm} / \mathrm{m}^{2}$} \\
\hline Acute & $2.3 \pm 0.7$ & $2.0 \pm 0.6$ & 0.7 \\
\hline FU & $2.6 \pm 0.7$ & $2.0 \pm 0.5$ & $<0.0001$ \\
\hline \multicolumn{4}{|l|}{ LV FS, \% } \\
\hline Acute & $28 \pm 10$ & $30 \pm 10$ & 0.6 \\
\hline $\mathrm{FU}$ & $23 \pm 11$ & $30 \pm 9$ & $<0.01$ \\
\hline \multicolumn{4}{|c|}{ LVmass, $\mathrm{g} / \mathrm{m}^{2}$} \\
\hline Acute & $143 \pm 21$ & $133 \pm 32$ & 0.6 \\
\hline FU & $154 \pm 58$ & $117 \pm 32$ & $<0.0001$ \\
\hline \multicolumn{4}{|c|}{ Left atrium, $\mathrm{cm}$} \\
\hline Acute & $4.5 \pm 1.4$ & $4.3 \pm 1.0$ & 0.9 \\
\hline FU & $4.6 \pm 1.0$ & $3.8 \pm 0.8$ & $<0.05$ \\
\hline \multicolumn{4}{|c|}{ RVDDI, $\mathrm{cm} / \mathrm{m}^{2}$} \\
\hline Acute & $1.4 \pm 0.5$ & $1.4 \pm 0.4$ & 0.9 \\
\hline $\mathrm{FU}$ & $1.5 \pm 0.3$ & $1.3 \pm 0.3$ & $<0.001$ \\
\hline \multicolumn{4}{|c|}{$\mathrm{RPAI}, \mathrm{cm} / \mathrm{m}^{2}$} \\
\hline Acute & $1.1 \pm 0.3$ & $1.1 \pm 0.3$ & 1.0 \\
\hline $\mathrm{FU}$ & $1.4 \pm 0.6$ & $1.1 \pm 0.2$ & $<0.05$ \\
\hline \multicolumn{4}{|c|}{$\mathrm{EDVI}, \mathrm{ml} / \mathrm{m}^{2}$} \\
\hline Acute & $71 \pm 3$ & $66 \pm 24$ & 0.4 \\
\hline $\mathrm{FU}$ & $92 \pm 34$ & $68 \pm 21$ & $<0.0001$ \\
\hline \multicolumn{4}{|c|}{ ESVI, $\mathrm{ml} / \mathrm{m}^{2}$} \\
\hline Acute & $39 \pm 14$ & $33 \pm 16$ & 0.7 \\
\hline FU & $58 \pm 30$ & $35 \pm 16$ & $<0.0001$ \\
\hline \multicolumn{4}{|l|}{ LVEF, \% } \\
\hline Acute & $46 \pm 11$ & $52 \pm 9$ & 0.7 \\
\hline FU & $41 \pm 14$ & $50 \pm 9$ & $<0.001$ \\
\hline
\end{tabular}

cially during the first 11 months, hardly any deaths occurred. Thereafter, i.e. in the chronic stage, mortality increased significantly, with a higher mortality in group I than in group II ( $\mathrm{p}=0.0002)$. Thus, $39 \%$ of group I patients deceased in comparison to only $9 \%$ in group II (odds ratio $=6.4697,95 \%$ confidence interval: $2.2110-18.931$ ). The causes of death are listed in table 3 , which underlines the fatal pathophysiological background of MR. Many more patients in group I died due to cardiogenic shock and ventricular fibrillation, whereas more patients in group II deceased from non-cardiological causes (table 3; lack of significance most probably due to small patient cohort).

\section{Discussion}

For the first time, this retrospective study investigated the chronic development of MR in a long-term post-MI study. Obviously, in one third of the patients who had suffered from an initially uncomplicated transmural MI, MR becomes chronic. This process is associated with relevant haemodynamic changes of LV performance, signs of pulmonary hypertension, and, what is more important, a more unfavourable prognostic outcome (odds ratio $=6.4697$ ). The hypothesis of this study was supported by increasing knowledge on the post-MI process: acute transmural MI may tend to result in LV remodelling with LV dilatation, which may principally be associated with the development of MR. As it is now well known that remodelling is a progressive, long-term disorder which may develop slowly over years (not only months) [12], we were convinced of the rationale to extent the follow-up beyond the (sub)acute hospital stay of MI patients (first echocardiogram $20 \pm 25$ days post-MI showing almost no MR and second echocardiogram $5.1 \pm 3.1$ years post-MI giving evidence of significant MR). The SAVE study [4] had still concluded that a prognostic effect of ischaemic MR can only be evaluated with the diagnosis of MR within and not beyond 16 days post-MI.

So far, clinical studies focussed primarily on acute and subacute MR rather than examining the chronic serial follow-up, with the largest data bases being from SAVE [4], Duke [13] and the Mayo Clinic [2]. MR in the acute phase is frequent $[1,2]$. Acute post-MI MR appears to result in an adverse prognosis $[1,2,4,5,13]$. However, in these earlier studies, only MR in (sub)acute MI were considered, and decreased survival of patients with ischaemic MR may have been due to the inclusion of patients with acute MI $[1,5]$. To the best of our knowledge, there is only one echocardiographic study with a postponed MR diagnosis post-MI, which had been performed by the Mayo Clinic [3]: 303 patients were examined $>16$ days after Q-wave MI (on average $86 \pm 90$ months). In agreement with our data, mortality was increased albeit with less chronically developed MR. Their relative risk of 1.88 was smaller within a comparable follow-up time period of 5 years in multivariate analysis (independent interpretation of baseline characteristics, particularly age and EF). However, in contrast to our study, they could not prove the chronic development of MR, since no serial echocardiograms had been performed, i.e. the number of (sub)acute types of ischaemic MR without severe dynamic changes was not known. A recent study even demonstrated significant MR following MI as an independent 
Fig. 1. Cumulative Kaplan-Meier survival curves (\%) comparing group I (continuous line) versus group II (interrupted line) as staircase lines with ticks at censored observations. Significance is according to the log-rank test.

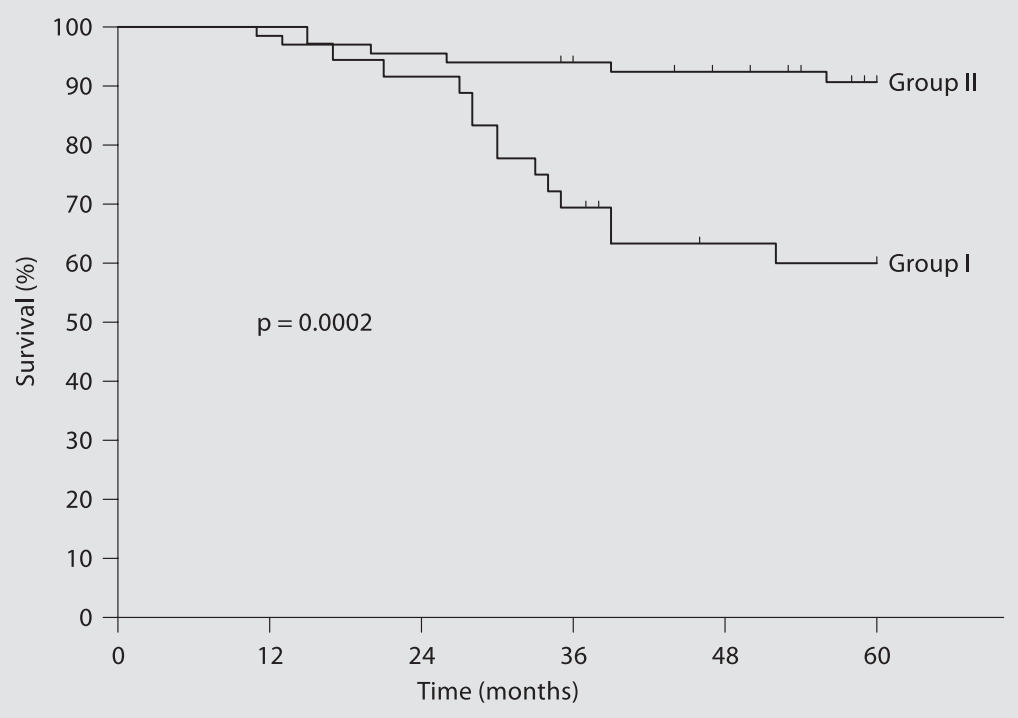

prognostic marker (relative risk: 3.8) [14], which could not be safely ruled out by the Mayo study.

In chronically developed MR, global LV remodelling might be the dominant feature; another echocardiographic study revealed a more functional insight by demonstrating, beside LV dilatation, more spherical ventricles and less endocardial curvature in post-MI MR patients, a typical pattern of remodelling [4]. Kono et al. [15] reported a more spherical LV cavity as the only difference between patients with MR and those without. These spherical dilated ventricles do impede appropriate leaflet coaptation; as the annulus is dilated, interpapillary muscle distance and leaflet tethering are increased, mitral leaflets are restricted to coapt at the annular plane, and closing forces are decreased [8]. Such global backgrounds of the remodelling process also seem to be relevant in our series, as beside volume enlargement (table 4), the sites of infarction were equally distributed in the MR groups (table 1). Circumscribed regional wall motion abnormalities as an independent cause of MR prevail in inferior MI [6], which has been postulated to be due to the particular vulnerability of the posterior papillary muscle with regard to its blood supply.

Our data provide evidence for the development of relative pulmonary hypertension, since RVDDI and RPAI increased during the follow-up only in the MR group, while these parameters tended to decrease in the non-MR group ( $\mathrm{p}<0.001$ and $\mathrm{p}<0.05$; table 4 ) [16]. Most probably, this might be the pathophysiological consequence of deteriorating LV systolic function [16] and rising filling pressures, a major determinant of ischaemic MR [16], which may be potentiated by the association of restrictive LV filling (not evaluated in this study due to variable effects of MR on transmitral Doppler profiles) [17] and resulting symptomatic congestive heart failure (New York Heart Association class: $\mathrm{p}=0.001$; table 2 ) and heart failure medications (the number of patients treated was increased in group I: glycosides, $\mathrm{p}<0.001$; ACE inhibitors, $\mathrm{p}=0.001$, and diuretics, $\mathrm{p}<0.001$; table 2 ), being comparable to other studies [3]. With regard to systolic LV dysfunction following non-compensated remodelling in the MR group in comparison to the non-MR group (EF, $\mathrm{p}<$ 0.001 , and LVFS, $\mathrm{p}<0.01$; table 4 ), it might be even underestimated due to an increase in potential relative artificial contractility due to volume overload. It may be supposed that ischaemic MR and the consecutive volume overload stimulate LV remodelling [18], which per se leads to long-term mortality [19]. However, further studies are required to draw definite conclusions on the effects of pathophysiological causes and consequences of MR in LV remodelling, but there might have been a haemodynamic effect of direct MR because the extent of infarction was similar (CK, nonsignificant) although LV volumes were significantly increased in MR patients (in 
agreement with the SAVE study [4]). Another reason could have been the generally greater severity of coronary artery disease in MR patients (multiple vessel disease; table 1; in accord with the SAVE study [4]) which was recently reported to affect the remodelling process besides the status of the infarction-related coronary artery $[20]$.

\section{Clinical Implications}

Since chronically developing post-MI MR is associated with increased mortality as it has been shown in a more acute scenery $[2,4,13]$, aggressive therapy is mandatory. The general principle of decreasing regurgitant volumes by vasodilators (most prominent by ACE inhibitors) is an important part of their clinical effect $[4,21$, 22]. In this context, the detection of LV remodelling (most adequately by serial Doppler echocardiography) is of pivotal importance because at a certain point of the remodelling process, $\mathrm{LV}$ dilatation may become irreversible and therefore no longer responsive to medical intervention [23]. Resynchronisation therapy by implantation of biventricular pacing systems could be a further possibility in reducing the degree of MR as a more homogeneous systolic performance might cause a decrease in chamber size and improve coordinated timing of the papillary muscle insertion sites [24]. Further prospective studies are required for this issue. Revascularisation by coronary artery bypass graft surgery seems to have a certain MRreducing effect, but additional mitral surgery remains to be defined [25]. Mitral valve repair/annuloplasty might be another surgical option in severe MR, but no mortality benefit has been demonstrated to date [26]. Very recently, the Boston group suggested chordal cutting to relieve chronic ischaemic MR which is still experimental [27]. In general, as there is at least evidence that ischaemic MR is more the consequence than the cause of LV remodelling [28], limiting infarction size will be the more important therapeutic target.

As a future perspective of the diagnostic procedure, it might be effective in certain patients to expand and scrutinize the transthoracic echocardiographic approach. Piérard and Lancellotti [29] demonstrated in ischaemic MR patients that pulmonary oedema was associated with increases in regurgitant volumes, exercise-induced changes in the effective regurgitant orifice area and in the trans-tricuspid pressure gradient.

\section{Limitations of the Study}

The diagnostic method of transthoracic echocardiography is highly accurate for anatomy, but colour
Doppler is fraught with errors in ischaemic MR [30]. As we were looking for a method facilitating convenient risk stratification in clinical practice, a simple semiquantitative grading by jet area sizes was applied, although more sophisticated algorithms are available (such as measuring the vena contracta, calculations of regurgitant fraction and volume or regurgitant orifice area by the proximal isovelocity surface area method $[3$, 30], or by calculating differences in mitral and aortic stroke volumes measured by pulsed-wave Doppler velocity-time integrals $[3,21])$. We are aware that jet areas tend to overestimate the degree of MR [31], and it is also known that mild post-MI MR has already prognostic implications [4]. On the other hand, serial catheterisations to document regurgitant contrast into the left atrium are invasive and surely not justified, but auscultation of the ischaemic MR murmur is of limited value [32] due to decreased turbulence.

We did not separate subgroups defined by different MR gradings, known to imply prognostic implications in LV dysfunction [33,34], due to imprecision in the semiquantitative method as well as the low number of patients. Only in part of the patients was tricuspid valve regurgitation investigated to obtain an estimation of pulmonary artery pressure, which would have been interesting for interpreting pulmonary hypertension [33]. Due to the lack of data we excluded this parameter.

We included consecutive patients in this particular study to avoid selection bias, but we did not adjust or match patients with and without MR regarding patient characteristics such as age and sex, for example, or LV performance (e.g. LVFS or EF). However, in spite of the study design, all patient characteristics and echocardiographic parameters (including LV size and function, nonsignificant) and even infarction location and size (CK, nonsignificant) were comparable in both groups. Merely the coronary anatomy differed $(\mathrm{p}=0.0138$; table 1). Also, for the whole study group, this retrospective study cannot be free of some recruiting bias. This seems especially true for the echocardiographic followup study, which might have been predominantly taken by patients being more ill. This might be one of the reasons for the relatively high occurrence of chronic MR in this study, compared to the (sub)acute MR data in the literature $[4,33]$ ), although a further, main reason may be the lack of interventional MI treatment in the recruiting period which does not correspond with present therapies.

Cardiology 2007;107:239-247 245 


\section{Conclusions}

This retrospective study underscores the importance of standardised transthoracic Doppler echocardiography to define the development of MR following MI. Due to its prognostic implications as well as its treatability by long- term pharmacological (mainly by reducing afterload) strategies, probably also by resynchronisation therapy [34], serial echocardiography is recommended in postMI patients. However, prospective multicentre trials are advisable to confirm these preliminary results on chronically developed MR in post-MI patients.

\section{References}

1 Barzilai B, Gessler C Jr, Perez JE, Schaab C, Jaffe AS: Significance of Doppler-detected mitral regurgitation in acute myocardial infarction. Am J Cardiol 1988;61:220-223.

2 Bursi F, Enriquez-Sarano M, Nkomo VT, Jacobsen SJ, Weston SA, Meverden RA, Roger VL: Heart failure and death after myocardial infarction in the community: the emerging role of mitral regurgitation. Circulation 2005;111:295-301.

3 Grigioni F, Enriquez-Sarano M, Zehr KJ, Bailey KR, Tajik AJ: Ischemic mitral regurgitation. Long-term outcome and prognostic implications with quantitative Doppler assessment. Circulation 2001;103:1759-1764.

4 Lamas GA, Mitchell GF, Flaker GC, Smith SC Jr, Gersh BJ, Basta L, Moye L, Braunwald E, Pfeffer MA: Clinical significance of mitral regurgitation after acute myocardial infarction. Survival and Ventricular Enlargement Investigators. Circulation 1997;96:827-833.

5 Lehmann KG, Francis CK, Dodge HT: Mitral regurgitation in early myocardial infarction: incidence, clinical detection, and prognostic implications: TIMI Study Group. Ann Intern Med 1992;117:10-17.

6 Mittal AK, Langston M, Cohn KE, Selzer A, Kerth W: Combined papillary muscle and left ventricular wall dysfunction as a cause of mitral regurgitation: an experimental study. Circulation 1971;44:174-180.

7 Nixdorff U, Rupprecht HJ, Mohr-Kahaly S, Wittlich N, Oelert H, Schmied W, Meyer J: Transesophageal echocardiography in cardiogenic shock due to inferior myocardial infarction with papillary muscle rupture. Z Kardiol 1994;83:495-501.

8 Nielsen SL, Nygaard H, Mandrup L, Fontaine AA, Hasenkam JM, He S, Yoganathan AP: Mechanism of incomplete mitral leaflet coaptation - interaction of chordal restraint and changes in mitral leaflet coaptation geometry. Insight from in vitro validation of the premise of force equilibrium. J Biomech Eng 2002;124:596-608.

9 Erbel R, Kneissel GD, Schweizer P, Lambertz HJ, Engberding R: Qualitätsleitlinien in der Echokardiographie. Z Kardiol 1997;86:387403.

10 Hoffmann R, Working Group Cardiovascular Ultrasound: Position paper on quality standards in echocardiography. Z Kardiol 2004;93:975-986.
11 Schiller NB, Shah PM, Crawford M, DeMaria A, Devereux R, Feigenbaum H, Gutgesell H, Reichek N, Sahn D, Schnittger I, et al: Recommendations for quantification of the left ventricle by two-dimensional echocardiography. American Society of Echocardiography Committee on Standards, Subcommittee on Quantitation of TwoDimensional Echocardiograms. J Am Soc Echocardiogr 1989;2:358-367.

12 Nixdorff U, Erbel R, Pop T, Rupprecht HJ, Henrichs KJ, Morchen S, Meyer Jl: Longterm follow-up of global and regional left ventricular function by two-dimensional echocardiography after thrombolytic therapy in acute myocardial infarction. Int J Cardiol 1993;41:31-47.

13 Hickey MS, Smith LR, Muhlbaier LH, Harrell FE Jr, Reves JG, Hinohara T, Califf RM, Pryor DB, Rankin JS: Current prognosis of ischemic mitral regurgitation. Implications for future management. Circulation 1988; 78:I-51-I-59.

14 Zamorano J, Perez de Isla L, Oliveros L, Almería C, Rodrigo JL, Aubele AA, Macaya C: Prognostic influence of mitral regurgitation prior to a first myocardial infarction. Eur Heart J 2005;26:343-349.

15 Kono T, Sabbah HN, Stein PD, Brymer JK, Khaja F: Left ventricular shape as a determinant of functional mitral regurgitation in patients with severe heart failure secondary to either coronary artery disease or idiopathic dilated cardiomyopathy. Am J Cardiol 1991;68:355-359.

16 Enriquez-Sarano M, Rossi A, Seward JB, Bailey KR, Tajik AJ: Determinants of pulmonary hypertension in left ventricular dysfunction. J Am Coll Cardiol 1997;29:153159.

17 Rihal CS, Nishimura RA, Hatle LK, Bailey KR, Tajik AJ: Systolic and diastolic dysfunction in patients with clinical diagnosis of dilated cardiomyopathy. Relation to symptoms and prognosis. Circulation 1994;90:27722779.

18 Pouleur HG, Konstam MA, Udelson JE, Rousseau MF: Changes in ventricular volume, wall thickness and wall stress during progression of left ventricular dysfunction. The SOLVD Investigators. J Am Coll Cardiol 1993;22:43A-48A.
19 St. John Sutton M, Pfeffer MA, Plappert T, Rouleau JL, Moye LA, Dagenais GR, Lamas GA, Klein M, Sussex B, Goldman S, et al: Quantitative two-dimensional echocardiographic measurements are major predictors of adverse cardiovascular events after acute myocardial infarction. The protective effects of captopril. Circulation 1994;89:68-75.

20 Konermann M, Sanner BM, Grotz J, Laschewski F, Josephs W, Odenthal HJ, Horstmann E: Effect of infarct size and site, patency of the infarct vessel and perfusion of vital myocardium on remodeling of the left ventricle - studies with cine-magnetic resonance tomography in the first 6 months following myocardial infarct. Z Kardiol 1996; 85:906-916.

21 Enriquez-Sarano M, Seward JB, Bailey KR, Tajik AJ: Effective regurgitant orifice area: a non-invasive Doppler development of an old hemodynamic concept. J Am Coll Cardiol 1994;23:443-451.

22 Stevenson LW, Bellil D, Grover-McKay M, Brunken RC, Schwaiger M, Tillisch JH, Schelbert HR: Effects of afterload reduction (diuretics and vasodilators) on left ventricular volume and mitral regurgitation in severe congestive heart failure secondary to ischemic or idiopathic dilated cardiomyopathy. Am J Cardiol 1987;60:654-658.

23 Levine AB, Muller C, Levine TB: Effects of high-dose lisinopril-isosorbide dinitrate on severe mitral regurgitation and heart failure remodeling. Am J Cardiol 1998;82:12991301.

24 Kanzaki H, Bazaz R, Schwartzman D, Dohi K, Sade LE, Gorcsan J III: A mechanism for immediate reduction in mitral regurgitation after cardiac resynchronization therapy. J Am Coll Cardiol 2004;44:1619-1625.

25 Trichon BH, Glower DD, Shaw LK, Cabell $\mathrm{CH}$, Anstrom KJ, Felker GM, O'Connor CM: Survival after coronary revascularization, with and without mitral valve surgery, in patients with ischemic mitral regurgitation. Circulation 2003;108(suppl II):II-103-II-110.

$26 \mathrm{Wu} \mathrm{AH}$, Aaronson KD, Bolling SF, Pagani FD, Welch K, Koelling TM: Impact of mitral valve annuloplasty on mortality risk in patients with mitral regurgitation and left ventricular systolic dysfunction. J Am Coll Cardiol 2005;45:381-387. 
27 Messas E, Pouzet B, Touchot B, Guerrero JL, Vlahakes GJ, Desnos M, Menasche P, Hagege A, Levine RA: Efficacy of chordal cutting to relieve chronic persistent ischemic mitral regurgitation. Circulation 2003;108(suppl II): II-111-II-115.

28 Guy TS IV, Moainie SL, Gorman JH III, Jackson BM, Plappert T, Enomoto Y, St. JohnSutton MG, Edmunds LH Jr, Gorman RC: Prevention of ischemic mitral regurgitation does not influence the outcome of remodeling after posterolateral myocardial infarction. J Am Coll Cardiol 2004;43:377-383.
29 Piérard LA, Lancellotti P: The role of ischemic mitral regurgitation in the pathogenesis of acute pulmonary edema. N Engl J Med 2004;351:1627-1634.

30 Enriquez-Sarano M, Miller FA Jr, Hayes SN, Bailey KR, Tajik AJ, Seward JB: Effective mitral regurgitant orifice area: clinical use and pitfalls of the proximal isovelocity surface area method. J Am Coll Cardiol 1995;25: 703-709.

31 McCully RB, Enriquez-Sarano M, Tajik AJ, Seward JB: Overestimation of severity of ischemic/functional mitral regurgitation by colour Doppler jet area. Am J Cardiol 1994; 74:790-793.
32 Desjardins VA, Enriquez-Sarano M, Tajik AJ, Bailey KR, Seward JB: Intensity of murmurs correlates with severity of valvular regurgitation. Am J Med 1996;100:149-156.

33 Koelling TM, Aaronson KD, Cody RJ, Bach DS, Armstrong WF: Prognostic significance of mitral regurgitation and tricuspid regurgitation in patients with left ventricular systolic dysfunction. Am Heart J 2002; 144:524529.

34 Trichon BH, O'Connor CM: Secondary mitral and tricuspid regurgitation accompanying left ventricular dysfunction: It is important, and how is it treated? Am Heart J 2002; 144:343-376. 